\title{
Percutaneous endoscopic gastrostomy assisted by laparoscopy: is it a valid choice?
}

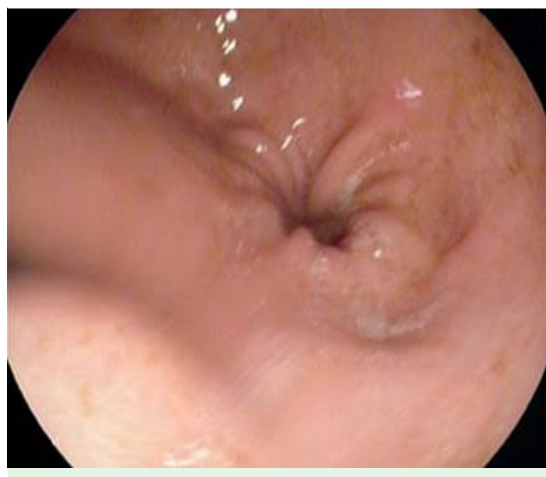

Fig. 1 Percutaneous endoscopic gastrostomy (PEG) was attempted to allow continuous levodopa infusion in a 65-year-old man with Parkinson's disease. Endoscopic access failed, because there was no transillumination, and hence the trocar could not be passed percutaneously to be visualized intraluminally by the gastroscope.

Percutaneous endoscopic gastrostomy (PEG) has become the procedure of choice for enteral feeding, with a relatively low risk of complications and a high success rate in $95 \%$ of cases [1]. Currently it offers a new approach to continuous infusion with levodopa in selected patients with Parkinson's disease. Nevertheless, certain patient characteristics can absolutely contraindicate the procedure [2,3].

A 65-year-old male patient with longstanding Parkinson's disease underwent stimulation of the right subthalamic nucleus in 2009. Continuous infusion of levodopa was then proposed. The treatment was initiated using a nasogastric tube, but the patient had low tolerance of this approach, and therefore PEG was decided upon. Two unsuccessful attempts at placement were made. Endoscopic access failed, because no transillumination could be seen, and hence the trocar could not be passed percutaneously to be visualized intraluminally by the gastroscope ( $\nabla$ Fig. 1 ). Subsequently, a radiological approach was attempted, with similar failure because of interposition of the large bowel, full of gas and stools, between the abdominal wall and the gastric cavity ( $\bullet$ Fig. 2 ).

Therefore, to permit continuous infusion of levodopa, a decision was made for a scheduled laparoscopically assisted PEG with the patient under general anesthesia.

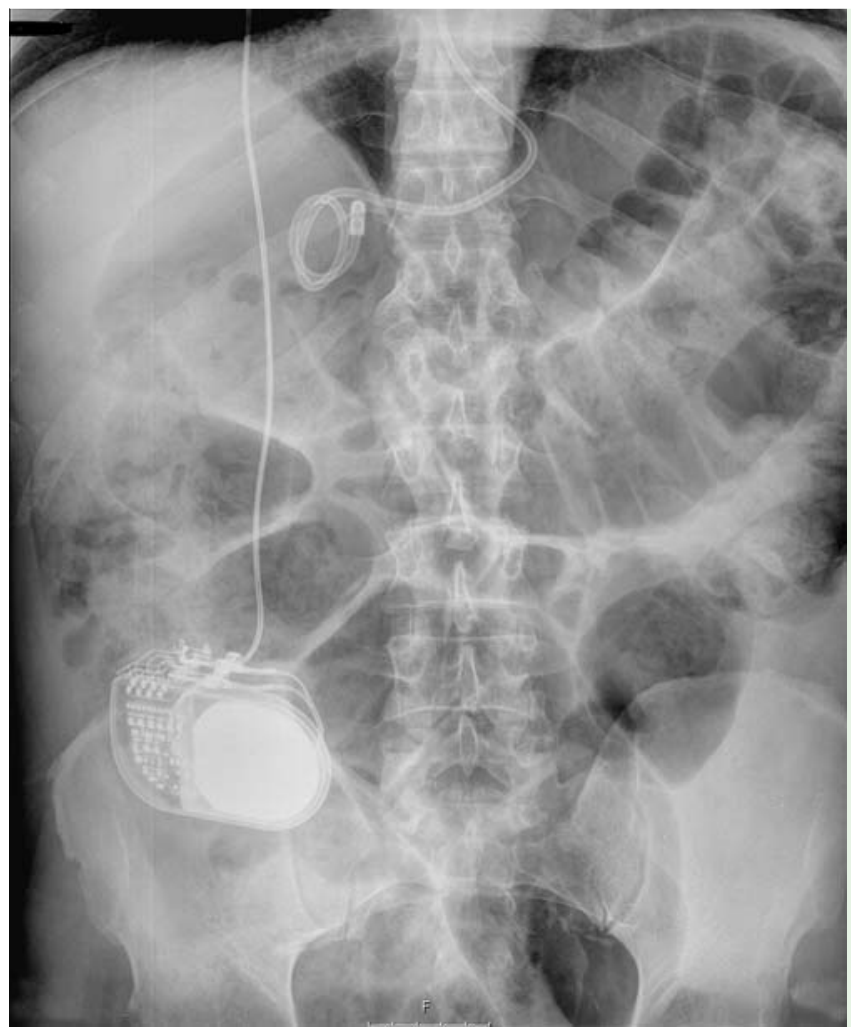

Fig. 2 A radiological approach also failed, because the large bowel, full of gas and stools, was interposed between the abdominal wall and gastric cavity.
This entailed direct visualization and gastric exposure. Using this simple and easy method, it was possible to displace the large bowel and correctly perform the procedure. The method gives two advantages: first, avoidance of damage to other organs, in this case the large bowel; and second, more accurate placement of the gastrostomy tube.

Currently, the patient is having continuous neurological monitoring, and is showing good response to treatment.

Interposition of the large bowel is a complication that can occur frequently. This is the first case reported in this type of patient. Performance of laparoscopically assisted PEG is a safe and effective alternative in such cases.

\section{Endoscopy_UCTN_Code_TTT_1AO_2AK}

\section{Competing interests: None}

\section{Laura Uribarri González ${ }^{1}$, José Iglesias Canle ${ }^{1}$, Purificación Parada Gonzalez², Andrea Castiñeira Perez ${ }^{2}$, J. Enrique Domínguez-Muñoz ${ }^{1}$}

${ }^{1}$ Department of Gastroenterology, Hospital Clínico Universitario de Santiago de Compostela, Santiago de Compostela, Spain

2 Department of General Surgery, Hospital Clínico Universitario de Santiago de Compostela, Santiago de Compostela, Spain

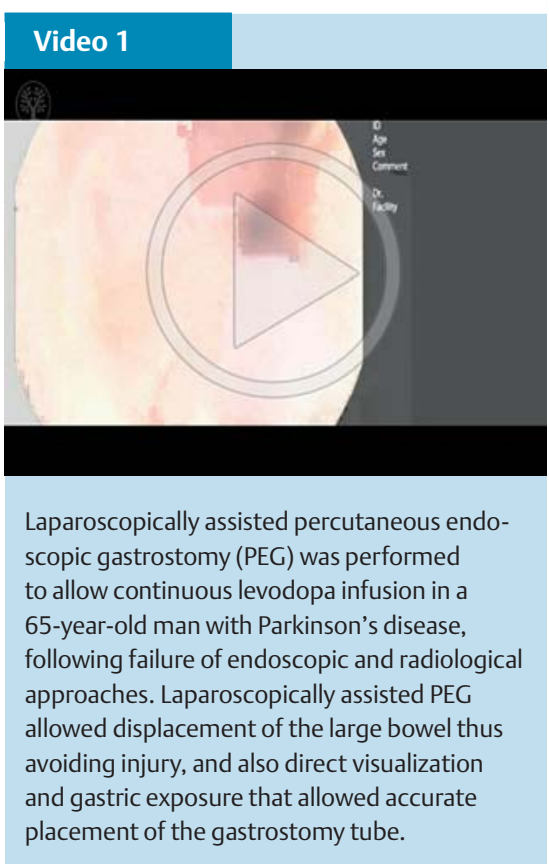




\section{References}

1 Larson DE, Burton DD, Schroeder KW et al. Percutaneous endoscopic gastrostomy. Indications, success, complications, and mortality in 314 consecutive patients. Gastroenterology 1987; 93: 48-52

2 Eisen GM, Baron TH, Dominitz JA et al. Role of endoscopy in enteral feeding. Gastrointest Endosc 2002; 55: $794-797$

3 Gauderer $M W$. Experience with a hybrid, minimally invasive gastrostomy for children with abnormal epigastric anatomy. J Pediatr Surg 2008; 43: $2178-2181$

\section{Bibliography}

DOI http://dx.doi.org/

10.1055/s-0042-100198

Endoscopy 2016; 48: E37-E38

(c) Georg Thieme Verlag KG

Stuttgart · New York

ISSN 0013-726X

\section{Corresponding author}

\section{Laura Uribarri González, MD}

Gastroenterology Department

Hospital Clínico Universitario Santiago Compostela

Travesía de Choupana

Santiago de Compostela

ES 15706

Fax: +34-981-950900

luribarrigonzalez@gmail.com 